\title{
Understanding the influence of high novelty-seeking on academic burnout: Moderating effect of physical activity
}

\author{
Mohsen Khosravi (1), Mahla Mirbahaadin (2), Rashya Kasaeiyan (3) \\ (1) Department of Psychiatry and Clinical Psychology, Baharan Psychiatric Hospital, Zahedan, \\ Sistan and Baluchestan, IR Iran: (2) Islamic Azad University Zahedan Branch, Zahedan, Sistan \\ and Baluchestan, IR Iran; (3) Department of Clinical Psychology, Shiraz University, Shiraz, \\ Fars, IR Iran
}

This article is distributed under the terms of the Creative Commons Attribution Noncommercial License (CC BY-NC 4.0) which permits any noncommercial use, distribution, and reproduction in any medium, provided the original author(s) and source are credited.

\begin{abstract}
A large number of studies have shown a positive correlation between high novelty-seeking (HNS), substance/medication use (S/MU), high physical activity (HPA), and academic burnout (AB); however, the outcome of individuals with HNS in the terms of catching AB is doubtful. The present study was conducted to find out whether the personality traits such as HNS in medical students predisposes the AB or decreases its severity by increased physical activity (PA). This cross-sectional study, 227 medical students with HNS were selected from three major cities of Iran during February, 2019 to July, 2019 using convenience sampling and were assessed using demographic information form, Baecke's physical activity questionnaire, and Breso's academic burnout questionnaire. In this study, 126 male and 151 female participants were divided into four groups namely HNS + low physical activity (LPA) $(\mathrm{n}=68)$; HNS + HPA $(\mathrm{n}=73)$; HNS + S/MU $+\mathrm{LPA}(\mathrm{n}=72)$; and HNS + S/MU + HPA $(\mathrm{n}=64)$. The study results indicated that the maximum and minimum mean scores of $\mathrm{AB}$ and its subscales were in the HNS + S/MU + LPA and HNS + HPA groups, respectively. In addition, the hierarchical multiple regression analysis results for the two groups of students with and without S/MU indicated that PA plays a moderating role in the relationship between $\mathrm{AB}$ and HNS. Given that the $\mathrm{AB}$ can be considered as an antecedent of depressive disorders, its lowered level could be effective in preventing major depressive disorder. Regarding the moderating role of PA in the relationship between HNS and AB, PA, as a relatively simple and inexpensive alternative to pharmacotherapy and psychotherapy, can be raised in the treatment and prevention of the $\mathrm{AB}$.
\end{abstract}

Key Words: Burnout, Novelty-seeking, Physical activity, Substance/medication use, Medical students.

Eur J Transl Myol 30 (2): 318-324, 2020

\begin{abstract}
Among academic students, medical students are more susceptible to academic stress, which, during a long term, may lead to frustration, exhaustion, helplessness, and cynicism through arousing academic burnout $(\mathrm{AB}){ }^{1}$ Freudenberger first discussed the critical role of personality in burnout. ${ }^{2}$ In their studies, Maslach and Jackson and Jacobs and Dodd then documented that the role of personality variables in predicting burnout was more highlighted than extrinsic environments. ${ }^{3,4}$ In this regard, Cloninger introduced a psychological model of personality, which encompassed four heritable temperament traits, including novelty-seeking, harm avoidance, reward dependence, and persistence. ${ }^{5}$ Among these traits, novelty-seeking is one of the traits defining
\end{abstract}

characteristics of a sensation-seeking personality in humans and seems to be associated with the AB. ${ }^{1,5}$ According to Zuckerman et al., sensation-seeking is a trait twinned with seeking for novel sensations and taking physical, social, legal, and financial risks for such experiences $;{ }^{6}$ hence, overpowering motivational strength in individuals with high novelty-seeking (HNS) may reduce the ability to control behaviors such as substance/medication use (S/MU). ${ }^{7}$ Furthermore, it may lead individuals towards self-medication through S/MU by establishing maladaptive levels of novelty-seeking behaviors and intrinsic disorders such as depression, anxiety, panic disorder, and burnout. ${ }^{8,9}$ In other words, the HNS is assumed to be an indicator of S/MU by posing a tendency towards novel stimuli and a quick response to 
cues for reward despite potential punishment. ${ }^{10}$ The assumption is further confirmed in accordance to the positive correlation between novelty-seeking behavior and vulnerability to extrinsic disorders such as S/MU. ${ }^{11}$ In addition, HNS might be associated with a structured physical activity (PA) thanks to some of its features, including extroversion, enthusiasm, intolerance of uniformity, high response to diversity, and high dynamism and curiosity. ${ }^{12} \mathrm{~A}$ recent meta-analysis has revealed that extroversion, which is conceptually correlated with novelty-seeking, has a positive effect on structured PA. ${ }^{13}$ Although a large number of studies have addressed the positive correlation between HNS, S/MU, $\mathrm{PA}$, and $\mathrm{AB},{ }^{1,8-14}$ but the outcome of individuals with HNS in the terms of catching $A B$ is doubtful. In the present study, the purpose was to compare the mean scores of $\mathrm{AB}$ at different $\mathrm{PA}$ levels among medical students with and without S/MU and examine the relationship between $\mathrm{HNS}$ and $\mathrm{AB}$ with regard to the moderating role of $\mathrm{PA}$ in order to answer the aforementioned research question.

\section{Materials and Methods}

\section{Study design and participants}

This research was a cross-sectional study conducted during February, 2019 to July, 2019. According to James Stevens, ${ }^{15}$ fifteen observations per predictor variable in multiple regression analysis can provide an acceptable rule of thumb. Regarding this rule and three predictor variables in the present study, a minimum of 45 was estimated for each group. Accordingly, 277 medical students with scores $>10$ from Cloninger's Temperament and Character Inventory were asked about drug use and then divided into two groups with and without S/MU. The participants were then assessed using demographic information form, Baecke's physical activity questionnaire, and Breso's academic burnout questionnaire. The university students with scores $>7.5$ from Baecke's physical activity questionnaire were considered as students with high physical activity (HPA), and the others were assumed as students with low physical activity (LPA). The participants were thus assigned to four groups namely HNS + LPA, HNS + $\mathrm{HPA}, \mathrm{HNS}+\mathrm{S} / \mathrm{MU}+\mathrm{LPA}$, and HNS + S/MU + HPA. Convenience sampling was used in the present study to select the participants from three major cities of Iran. Exclusion criteria were unwillingness to participate in the study, suffering from a major psychiatric or medical disorder, and improper completion of the questionnaires. In order to fully comply with the Helsinki principles, the participants' informed consent was obtained before conducting the study. This study was confirmed by the Committee for Ethics in Research in the Medical University of Zahedan (IR.ZAUMS.REC.1398.190).

\section{Measures}

Demographic Information Form
The form was developed by the researcher and contained a variety of variables such as age, gender, relational status, residence, income, years in medical school, and S/MU.

\section{Baecke's physical activity questionnaire}

This scale encompassed 25 items covering different features of PA in three sections: different physical conditions; first and second exercise; and PA at leisure time. The items were scored based on a 5-point Likert scale ranging from 1 to 5, with the maximum score of 15 . The reliability and validity of its Farsi version were assessed as acceptable (Cronbach's alpha $=0.78) .{ }^{16}$

\section{Temperament and Character Inventory}

This inventory with 125 items contains the components of temperament (novelty-seeking, harm avoidance, reward dependence, and persistence) and character (selfdirectedness, cooperativeness, self- transcendence). The novelty-seeking score ranged from zero to 20 , with the scores $>10$ being set as HNS in this study. The validity and reliability of its Farsi version were approved by Dadfar et al (Cronbach's alpha $=0.74) .{ }^{17}$

Breso's academic burnout questionnaire

The questionnaire measures three aspects of $\mathrm{AB}$ (i.e., exhaustion, cynicism, and inefficacy). The 15-item questionnaire is scored based on 5-point Likert scale ranging from strongly disagree to strongly agree. The minimum and maximum scores from this questionnaire were 15 and 75, respectively. Its reliability and validity in Iran are reported as acceptable (Cronbach's alpha of exhaustion, cynicism, and inefficacy are $0.70,0.82$, and 0.75 , respectively). ${ }^{18}$

\section{Statistical Analysis}

Descriptive statistics such as mean and standard deviation were used to analyze the data. Kruskal-Wallis and analysis of variance (ANOVA) tests were used to compare the data collected from different groups, and Cramer's V test, Spearman's rank correlation coefficient, and Pearson's correlation coefficient were also adopted to assess the correlation between the research variables. Moreover, hierarchical multiple regression analysis was run to evaluate the moderating effect of predictor variables in the two groups of students with and without $\mathrm{S} / \mathrm{MU}$. For this purpose, the predictor variables in the first and second stages and the interaction HNS $\times$ PA in the third stage were added to the analysis. SPSS software version 25 was used for data analysis and the level of significance was set to be $<0.05$.

\section{Results}

In the present study, 277 medical students with HNS (126 men and 151 women) were examined in four groups: HNS + LPA $(n=68) ; \mathrm{HNS}+\mathrm{HPA}(\mathrm{n}=73) ; \mathrm{HNS}+\mathrm{S} / \mathrm{MU}$ + LPA $(n=72)$; and HNS + S/MU + HPA $(n=64)$. Table 1 presents the frequency and percentage of demographic variables as well as the mean scores of HNS, PA, 
Table 1. The frequency and percentage of demographic variables as well as the mean scores of high novelty-seeking, physical activity, exhaustion, cynicism, inefficacy, and academic burnout in all of the groups

\begin{tabular}{|c|c|c|c|c|c|c|}
\hline Variables & & & $\begin{array}{l}\text { HNS + LPA } \\
\quad(n=68)\end{array}$ & $\begin{array}{c}\mathrm{HNS}+\mathrm{HPA} \\
(\mathrm{n}=73)\end{array}$ & $\begin{array}{c}\mathrm{HNS}+\mathrm{S} / \mathrm{MU}+\mathrm{LPA} \\
(\mathrm{n}=72)\end{array}$ & $\begin{array}{c}\mathrm{HNS}+\mathrm{S} / \mathrm{MU}+\mathrm{HPA} \\
(\mathrm{n}=64)\end{array}$ \\
\hline \multirow{2}{*}{ Age } & $\leq 24$ & $\mathrm{~N}(\%)$ & $39(57.4)$ & $39(54.2)$ & $42(57.5)$ & $35(54.7)$ \\
\hline & $>24$ & $\mathrm{~N}(\%)$ & $29(42.6)$ & $33(45.8)$ & $31(42.5)$ & $29(45.3)$ \\
\hline$\chi^{2}(\mathrm{df})$ & \multicolumn{6}{|c|}{$0.262(3)$} \\
\hline $\mathrm{P}$ & \multicolumn{6}{|c|}{0.967} \\
\hline \multirow{2}{*}{ Gender } & Male & $\mathrm{N}(\%)$ & $31(45.6)$ & $33(45.8)$ & 34 (46.6) & $28(43.8)$ \\
\hline & Female & $\mathrm{N}(\%)$ & $37(54.4)$ & $39(54.2)$ & $39(53.4)$ & $36(56.3)$ \\
\hline$\chi^{2}(\mathrm{df})$ & \multicolumn{6}{|c|}{$0.116(3)$} \\
\hline $\mathrm{P}$ & \multicolumn{6}{|c|}{0.990} \\
\hline \multirow{3}{*}{$\mathrm{RS}$} & Single & $\mathrm{N}(\%)$ & $62(91.2)$ & $57(72.9)$ & $65(89)$ & $55(85.9)$ \\
\hline & Married & $\mathrm{N}(\%)$ & $6(8.8)$ & $15(20.8)$ & $8(11)$ & $7(10.9)$ \\
\hline & Others & $\mathrm{N}(\%)$ & $0(0)$ & $0(0)$ & $0(0)$ & $2(3.1)$ \\
\hline$\chi^{2}(\mathrm{df})$ & \multicolumn{6}{|c|}{$4.861(3)$} \\
\hline $\mathrm{P}$ & \multicolumn{6}{|c|}{0.182} \\
\hline \multirow{3}{*}{ Residence } & With Family & $\mathrm{N}(\%)$ & $21(30.9)$ & $19(26.4)$ & $24(32.9)$ & $21(32.8)$ \\
\hline & Dormitory & $\mathrm{N}(\%)$ & $41(60.3)$ & $34(47.2)$ & $34(46.6)$ & $34(53.1)$ \\
\hline & Tenant & $\mathrm{N}(\%)$ & $6(8.8)$ & $19(26.4)$ & $15(20.5)$ & $9(14.1)$ \\
\hline$\chi^{2}(\mathrm{df})$ & \multicolumn{6}{|c|}{$3.777(3)$} \\
\hline $\mathrm{P}$ & \multicolumn{6}{|c|}{0.287} \\
\hline \multirow{2}{*}{ Income } & $\leq \$ 100$ & $\mathrm{~N}(\%)$ & $46(67.6)$ & $41(56.9)$ & $48(65.8)$ & $32(50)$ \\
\hline & $>\$ 100$ & $\mathrm{~N}(\%)$ & $22(32.4)$ & $31(43.1)$ & $25(34.2)$ & $32(50)$ \\
\hline$\chi^{2}(\mathrm{df})$ & \multicolumn{6}{|c|}{$5.594(3)$} \\
\hline $\mathrm{P}$ & \multicolumn{6}{|c|}{0.133} \\
\hline \multirow{5}{*}{ YIMS } & First & $\mathrm{N}(\%)$ & $23(33.8)$ & $12(16.7)$ & $22(30.1)$ & $18(28.1)$ \\
\hline & Second & $\mathrm{N}(\%)$ & $10(14.7)$ & $12(16.7)$ & $15(20.5)$ & $9(14.1)$ \\
\hline & Third & $\mathrm{N}(\%)$ & $9(13.2)$ & $8(11.1)$ & $5(6.8)$ & $4(6.3)$ \\
\hline & Fourth & $\mathrm{N}(\%)$ & $11(16.2)$ & $26(36.1)$ & $17(23.3)$ & $18(28.1)$ \\
\hline & Others & $\mathrm{N}(\%)$ & $15(22.1)$ & $14(19.4)$ & $14(19.2)$ & $15(23.4)$ \\
\hline$\chi^{2}(\mathrm{df})$ & \multicolumn{6}{|c|}{$3.930(3)$} \\
\hline $\mathrm{P}$ & \multicolumn{6}{|c|}{0.269} \\
\hline HNS & & $\mathrm{M}(\mathrm{SD})$ & $11.941(0.895)$ & $11.861(1.025)$ & $11.958(0.823)$ & $11.828(0.746)$ \\
\hline $\mathrm{F}(3,273)$ & \multicolumn{6}{|c|}{0.346} \\
\hline $\mathrm{P}$ & \multicolumn{6}{|c|}{0.792} \\
\hline $\mathrm{PA}$ & & $\mathrm{M}(\mathrm{SD})$ & $4.881(0.913)$ & $8.677(1.495)$ & $6.290(1.179)$ & $9.587(1.703)$ \\
\hline $\mathrm{F}(3,273)$ & \multicolumn{6}{|c|}{172.513} \\
\hline $\mathrm{P}$ & \multicolumn{6}{|c|}{0.000} \\
\hline Exhaustion & & $\mathrm{M}(\mathrm{SD})$ & 15.647 (3.999) & $12.263(2.969)$ & $19.274(3.830)$ & $15.390(2.676)$ \\
\hline $\mathrm{F}(3,273)$ & & & & 50.777 & & \\
\hline $\mathrm{P}$ & & & & 0.000 & & \\
\hline Cynicism & & $\mathrm{M}(\mathrm{SD})$ & $11.661(2.904)$ & $8.472(2.599)$ & $14.904(3.078)$ & $13.484(2.606)$ \\
\hline $\mathrm{F}(3,273)$ & & & & 69.967 & & \\
\hline $\mathrm{P}$ & & & & 0.000 & & \\
\hline Inefficacy & & $\mathrm{M}(\mathrm{SD})$ & $19.544(3.918)$ & $13.944(3.179)$ & 21.945 (4.669) & $18(3.295)$ \\
\hline $\mathrm{F}(3,273)$ & & & & 55.635 & & \\
\hline $\mathrm{p}$ & & & & 0.000 & & \\
\hline $\mathrm{AB}$ & & $\mathrm{M}(\mathrm{SD})$ & $46.705(5.611)$ & $34.722(4.578)$ & $56.438(7.613)$ & 46.609 (2.229) \\
\hline $\mathrm{F}(3,273)$ & & & & 193.173 & & \\
\hline $\mathrm{p}$ & & & & 0.000 & & \\
\hline
\end{tabular}

$\mathrm{AB}$, academic burnout; HNS, high novelty-seeking; HPA, high physical activity; LPA, low physical activity; PA, physical activity; RS, relational status; S/MU, substance/medication use; YIMS, years in medical school.

exhaustion, cynicism, inefficacy, and AB. As shown in this table, there was no significant difference among the four groups regarding demographic variables of age $(\mathrm{p}=$ $\left.0.967, \chi^{2}(3)=0.262\right)$, gender $\left(p=0.990, \chi^{2}(3)=0.116\right)$, relational status $\left(\mathrm{P}=0.182, \chi^{2}(3)=4.861\right)$, residence $(\mathrm{p}$ $\left.=0.287, \chi^{2}(3)=3.777\right)$, income $\left(p=0.133, \chi^{2}(3)=\right.$ $5.594)$, and years in medical school $\left(\mathrm{p}=0.269, \chi^{2}(3)=\right.$ 3.930). Furthermore, no significant difference was noticed for the mean scores of HNS in the four study groups $(\mathrm{p}=0.792, \mathrm{~F}(3,273)=0.346)$. In contrast, a 


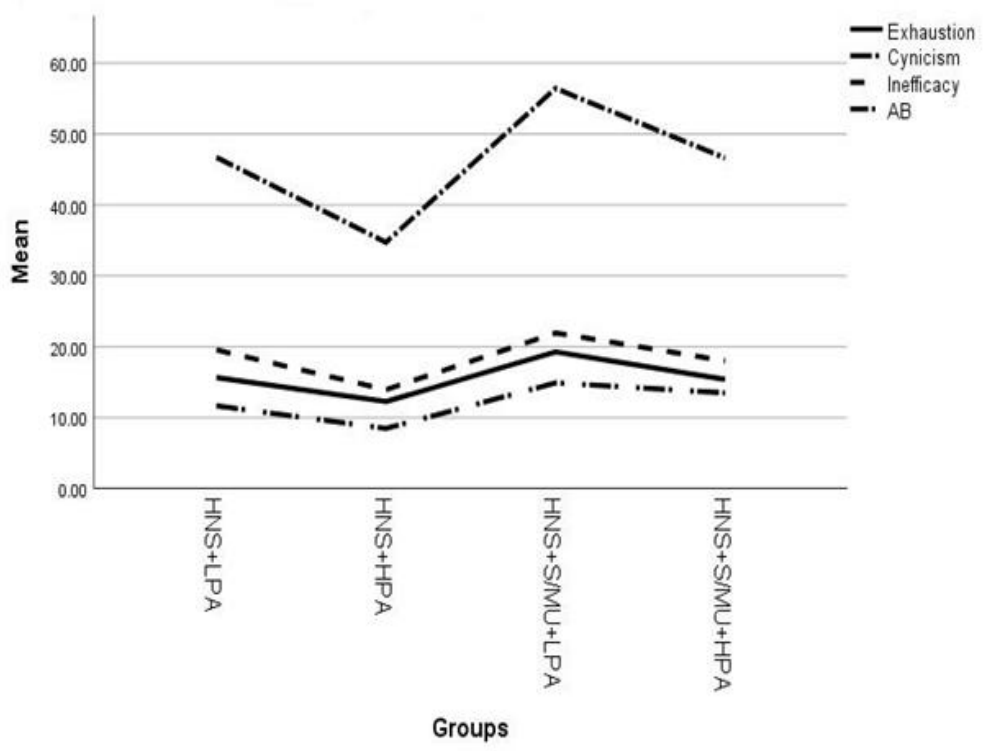

Fig 1. Multiple Line Mean of Exhaustion, Mean of Cynicism, Mean of Inefficacy, Mean of academic burnout by Group by INDEX

significant difference was reported among the mean scores of PA in the study groups $(\mathrm{p}=0.000, \mathrm{~F}(3,273)=$ 172.513). In addition, the participants' mean scores of AB $(\mathrm{p}=0.000, \mathrm{~F}(3,273)=193.173)$ and its subscales including exhaustion $(\mathrm{p}=0.000, \mathrm{~F}(3,273)=50.777)$, cynicism $(\mathrm{p}=0.137, \mathrm{~F}(3,273)=69.967)$, and inefficacy $(\mathrm{p}=0.000, \mathrm{~F}(3,273)=55.635)$ also had a significant difference among the study groups, as illustrated in Figure 1.

In Table 2, the results of the correlation for the study variables indicate a positive and moderate correlation between $\mathrm{AB}$ and $\mathrm{HNS}(\mathrm{p}<0.01, \mathrm{r}=0.338)$ and a negative and moderate correlation between $\mathrm{AB}$ and $\mathrm{PA}(\mathrm{p}<0.01$, $\mathrm{r}=-0.661$ ) among the students without S/MU. In the group of students with S/MU, the intensity and direction of correlation between the AB with HNS and PA were similar $(\mathrm{p}<0.01$ เ $\mathrm{r}=0.394$ $\mathrm{p}<0.01$ เ $\mathrm{r}=-0.469$, respectively).
Afterwards, the above variables were compared using the regression analysis for the two groups with and without $\mathrm{S} / \mathrm{MU}$ in order to investigate the moderating role of PA in the relationship between AB and HNS. In the group of students without S/MU, the HNS was first entered into the regression analysis and could significantly predict the $\mathrm{AB}\left(\mathrm{p}<0.001, \mathrm{R}^{2}=0.114, \beta=0.338\right)$. In the second stage, with controlling the effect of the HNS, the PA was entered into the analysis and could significantly predict the $A B\left(p<0.001, \Delta R^{2}=0.425, \beta=-0.652\right)$. In the third step, with controlling the effects of the predictor variables, the interaction HNS $\times$ PA was analyzed, and it was found that the PA played a moderating role in the relationship between $\mathrm{AB}$ and $\mathrm{HNS}\left(\mathrm{p}<0.01, \Delta \mathrm{R}^{2}=\right.$ $0.035, \beta=-2.425$ ). The results of the regression analysis in the S/MU group also revealed similar results. In this group, the HNS was first added to the regression analysis and could significantly predict the $\mathrm{AB}\left(\mathrm{p}<0.001, \mathrm{R}^{2}=\right.$

Table 2. The results of correlation between academic burnout and other study variables

\begin{tabular}{|c|c|c|c|c|c|c|c|c|}
\hline \multicolumn{9}{|c|}{ Without S/MU } \\
\hline & \multicolumn{4}{|c|}{ Cramer's V } & \multicolumn{2}{|c|}{$\begin{array}{c}\text { Spearman's rank correlation } \\
\text { coefficient }(\mathrm{r})\end{array}$} & \multicolumn{2}{|c|}{$\begin{array}{l}\text { Pearson correlation } \\
\text { coefficient }(r)\end{array}$} \\
\hline Variables & Age & Gender & $\mathrm{RS}$ & Residence & Income & YIMS & HNS & PA \\
\hline $\mathrm{AB}$ & 0.534 & 0.484 & 0.521 & 0.542 & -0.114 & -0.036 & $0.338^{* *}$ & $-0.661^{* *}$ \\
\hline \multicolumn{9}{|c|}{ With S/MU } \\
\hline & \multicolumn{4}{|c|}{ Cramer's V } & \multicolumn{2}{|c|}{$\begin{array}{l}\text { Spearman's rank correlation } \\
\text { coefficient (r) }\end{array}$} & \multicolumn{2}{|c|}{$\begin{array}{l}\text { Pearson correlation } \\
\text { coefficient }(r)\end{array}$} \\
\hline Variables & Age & Gender & RS & Residence & Income & YIMS & HNS & PA \\
\hline $\mathrm{AB}$ & 0.504 & 0.504 & 0.357 & 0.471 & -0.151 & 0.071 & $0.394^{* *}$ & $-0.469^{* *}$ \\
\hline \multicolumn{9}{|c|}{$\begin{array}{l}\text { AB, academic burnout; HNS, high novelty-seeking; PA, physical activity; RS, relational status; S/MU, substance/medication us } \\
\text { YIMS, years in medical school. }\end{array}$} \\
\hline${ }^{* * *} \mathrm{p}<0.01$ & signific & & & & & & & \\
\hline
\end{tabular}


Table 3. The results of the hierarchical multiple regression analysis

\begin{tabular}{|c|c|c|c|c|c|c|c|}
\hline \multicolumn{8}{|c|}{ Without S/MU } \\
\hline & & \multicolumn{2}{|l|}{ Model 1} & \multicolumn{2}{|l|}{ Model 2} & \multicolumn{2}{|l|}{ Model 3} \\
\hline & & $\mathrm{B}(\beta)$ & SEB & $\mathrm{B}(\beta)$ & SEB & $\mathrm{B}(\beta)$ & SEB \\
\hline Stage I: predictors & HNS & $2.765(0.338)^{* * * *}$ & 0.656 & $2.627(0.321)^{* * * *}$ & 0.475 & $7.585(0.926)^{* * *}$ & 1.559 \\
\hline Stage II: predictors & PA & & & $-2.259(-0.652)^{* * *}$ & 0.201 & $5.902(1.704)^{*}$ & 2.461 \\
\hline Stage III: moderator & $\mathrm{HNS} \times \mathrm{PA}$ & & & & & $-0.687(-2.425)^{* *}$ & 0.207 \\
\hline $\mathrm{R}^{2}$ & & \multicolumn{2}{|l|}{0.114} & \multicolumn{2}{|l|}{0.539} & \multicolumn{2}{|l|}{0.574} \\
\hline Adj. $\mathrm{R}^{2}$ & & \multicolumn{2}{|l|}{0.108} & \multicolumn{2}{|l|}{0.533} & \multicolumn{2}{|l|}{0.565} \\
\hline$\Delta \mathrm{R}^{2}$ & & \multicolumn{2}{|l|}{0.114} & \multicolumn{2}{|l|}{0.425} & \multicolumn{2}{|l|}{0.035} \\
\hline$\Delta \mathrm{F}(\mathrm{df})$ & & \multicolumn{2}{|c|}{$17.767(1,138)^{* * * *}$} & \multicolumn{2}{|c|}{$126.420(1,137)^{* * * *}$} & \multicolumn{2}{|c|}{$11.065(1,136)^{* * *}$} \\
\hline $\mathrm{F}(\mathrm{df})$ & & \multicolumn{2}{|c|}{$17.767(1,138)^{* * * * *}$} & \multicolumn{2}{|c|}{$80.167(2,137)^{* * * *}$} & \multicolumn{2}{|c|}{$61.060(3,136)^{* * * *}$} \\
\hline \multicolumn{8}{|c|}{ With S/MU } \\
\hline & & \multicolumn{2}{|l|}{ Model 1} & \multicolumn{2}{|l|}{ Model 2} & \multicolumn{2}{|l|}{ Model 3} \\
\hline & & $\mathrm{B}(\beta)$ & SEB & $\mathrm{B}(\beta)$ & $\mathrm{B}(\beta)$ & SEB & $\mathrm{B}(\beta)$ \\
\hline Stage I: predictors & HNS & $3.782(0.394)^{* * * *}$ & 0.759 & $2.976(0.310)^{* * * *}$ & 0.702 & $10.891(1.135)^{* * * *}$ & 2.364 \\
\hline Stage II: predictors & $\mathrm{PA}$ & & & $-1.398(-0.405)^{* * * *}$ & 0.253 & $11.182(3.241)^{* *}$ & 3.609 \\
\hline Stage III: moderator & $\mathrm{HNS} \times \mathrm{PA}$ & & & & & $-1.066(-3.575)^{* *}$ & 0.305 \\
\hline $\mathrm{R}^{2}$ & & \multicolumn{2}{|l|}{0.155} & \multicolumn{2}{|l|}{0.313} & \multicolumn{2}{|l|}{0.370} \\
\hline Adj. $R^{2}$ & & \multicolumn{2}{|l|}{0.149} & \multicolumn{2}{|l|}{0.302} & \multicolumn{2}{|l|}{0.356} \\
\hline$\Delta \mathrm{R}^{2}$ & & \multicolumn{2}{|l|}{0.155} & \multicolumn{2}{|l|}{0.158} & \multicolumn{2}{|l|}{0.057} \\
\hline$\Delta \mathrm{F}(\mathrm{df})$ & & \multicolumn{2}{|c|}{$24.850(1,135)^{* * *}$} & \multirow{2}{*}{\multicolumn{2}{|c|}{$\frac{30.613(1,134)^{* * *}}{30.457(2,134)^{* * *}}$}} & $12.205(1,133$ & \\
\hline $\mathrm{F}(\mathrm{df})$ & & $24.850(1,13$ & & & & $26.071(3,133$ & \\
\hline
\end{tabular}

$0.155, \beta=0.394)$. With controlling the effect of the HNS, the PA was then entered into the analysis and predicted the AB significantly $\left(\mathrm{p}<0.001, \Delta \mathrm{R}^{2}=0.158, \beta=-0.405\right)$. With controlling for the effect of the predictor variables in the third step, the interaction HNS $\times$ PA was analyzed and suggested the moderating role of the PA in the relationship between $\mathrm{AB}$ and $\mathrm{HNS}\left(\mathrm{p}<0.01, \Delta \mathrm{R}^{2}=\right.$ $0.057, \beta=-3.575$ ) (Table 3).

\section{Discussion}

This study aimed to compare the mean scores of $\mathrm{AB}$ at different PA levels among medical students with and without S/MU and examine the moderating role of PA in the relationship between HNS and AB. The study results revealed that the minimum and maximum mean scores of $\mathrm{AB}$ and its subscales in the HNS + S/MU + LPA and the HNS + HPA groups. This finding was in line with the findings of Gerber et al. ${ }^{19}$ as they documented that moderate intensity exercise can be accompanied with reduced overall perceived stress and burnout as well as improved mood. There are several reasons to explain this finding and the findings of the present study. First, the $\mathrm{PA}$ could lower the $\mathrm{AB}$ through increasing mastery learning and improving the potentials to cope with negative thoughts, modifying emotional action tendencies as a major therapeutic strategy, according to Barlow, Allen, and Choate, temporarily removing individuals from stress, and providing them with the opportunity to renew the personal measures needed to deal with job demands. Second, the PA may decrease emotional exhaustion through improving sleep conditions and recovery. ${ }^{20}$ Third, close contact with others during exercise sessions and the promotion of personal and social resources can reduce inattention through increasing social support. ${ }^{21}$ Fourth, reducing individual's physical vulnerability to stress through increasing heart rate and blood pressure and enhancing access to central neurotransmitters such as serotonin and endogenous opioids in charge of the antidepressant effects in the body, PA may prevent academic burnout and show comparable effects to antidepressants and cognitive-behavior therapy. ${ }^{22}$

Further, the results of correlation matrix for the study variables in the two groups of students with and without S/MU showed a positive and moderate correlation between $A B$ and HNS which were in a similar vein with the findings of Lee et al. ${ }^{1}$ and Yazici et al. ${ }^{14}$ A negative and moderate correlation was found between $\mathrm{AB}$ and PA, and this finding was in line with the findings of Lindwall et al. ${ }^{23}$ Tocker et al. ${ }^{24}$ and Jonsdottir et al. ${ }^{25}$ According to Schaufeli and Enzmann, ${ }^{26}$ there is a conceptual overlap between major depressive disorders and burnout subscales. As an example, fatigue or low levels of energy as the central component of all burnout assessment measures and major depressive disorder on the one hand, and the similarity of cynicism in burnout to social withdrawal and learned helplessness in major depressive disorder, on the other hand, ${ }^{28}$ further confirms such an overlap. Considering the positive effect of exercise on depressive disorder research, the hypothesis indicating the positive effect of exercise on burnout is also supported. The findings of the present study suggesting 
the moderating effect of PA on the relationship between HNS and AB may also support this hypothesis.

The present study had some limitations. First, due to the small sample size and the selection of participants from a specific geographical area, caution should be exercised in generalizing the findings of this study to other communities. Similar studies are also recommended to be conducted in other areas. Second, other factors (e.g., social support, comorbidities of psychiatric disorders especially anxiety and depression, workload, and others), which may affect the $\mathrm{AB}$ in the medical students should also be considered in future studies. Finally, the results of regression analysis in the two groups of medical students with and without S/MU showed that $5.7 \%$ and $3.5 \%$ of the $\mathrm{AB}$ were explained by $\mathrm{PA} \times \mathrm{HNS}$, indicating a relatively negligible and limited effect. With regard to the complexities of human studies, negligible moderating effects may also be significant so that health policy makers need to be cautious when designing preventive interventions.

Preliminary results of this study suggested that the HNS alone or in combination with S/MU predisposes the AB; however, if combined with HPA, this trait may reduce the risk of the $A B$ even in the presence of S/MU. Since the $\mathrm{AB}$ can be assumed an antecedent of depressive disorders, its reduction can be effective in preventing major depressive disorder. With regard to the moderating role of the PA in the relationship between HNS and AB, exercise interventions in the treatment and prevention of the $\mathrm{AB}$ can be considered as a relatively simple and inexpensive alternative to pharmacotherapy and psychotherapy. In addition to the positive effects of exercise on psychological well-being, its positive effects on physiological mechanisms such as metabolic and cardiovascular diseases should not be disregarded.

\section{List of acronyms}

$\mathrm{AB}$ - academic burnout HNS - high novelty-seeking

HPA - high physical activity

LPA - low physical activity

PA - physical activity

RS - Relational Status

S/MU - substance/medication use

YIMS - Years in Medical School

\section{Author's contributions}

All authors played a substantial role in study design, data acquisition and/or analysis, as well as in drafting of the manuscript.

\section{Acknowledgments}

The authors hereby thank the officials in charge of Zahedan University of Medical Sciences as well as the participants, who aided in conducting the present study.

\section{Funding}

No funding was received for this study.

\section{Conflict of Interest}

The authors have no conflicts to disclose.

\section{Ethical Publication Statement}

This study was confirmed by the Committee for Ethics in Research in the Medical University of Zahedan (IR.ZAUMS.REC.1398.190).

\section{Corresponding Author}

Mohsen Khosravi, MD, Assistant Professor, Department of Psychiatry and Clinical Psychology, Baharan Psychiatric Hospital, Zahedan University of Medical Sciences, Postal Code: 9813913777, Zahedan, IR Iran.

Tel: +98-5433522636; Fax: +98-5433518352

ORCID iD: 0000-0003-2970-6309

E-mail: m.khosravi@zaums.ac.ir

E-mails of co-authors

Mahla Mirbahaadin: mahlamirbahaadin@gmail.com ORCID iD: 0000-0002-5570-4633

Rashya Kasaeiyan: kasaeiyanr@yahoo.com

ORCID iD: 0000-0002-1264-6445

\section{References}

1. Lee SJ, Choi YJ, Chae H. The effects of personality traits on academic burnout in Korean medical students. Integrative medicine research. 2017;6:207-13.

2. Freudenberger HJ. Staff burnout. Journal of social issues 1974;30:159-65.

3. Maslach C, Jackson SE. The measurement of experienced burnout. Journal of organizational behavior 1981;2:99-113.

4. Jacobs SR, Dodd D. Student burnout as a function of personality, social support, and workload. Journal of college student development 2003;44:291-303.

5. Cloninger CR, Svrakic DM, Przybeck TR. A psychobiological model of temperament and character. The development of psychiatry and its complexity 1998;50:1-6.

6. Zuckerman M, Kuhlman DM, Joireman J, Teta P, et al. A comparison of three structural models for personality: the big three, the big five, and the alternative five. Journal of personality and social psychology 1993;65:757.

7. Wingo T, Nesil T, Choi JS, Li MD. Novelty seeking and drug addiction in humans and animals: from behavior to molecules. Journal of Neuroimmune Pharmacology 2016;11:456-70.

8. Khan AA, Jacobson KC, Gardner CO, et al. Personality and comorbidity of common psychiatric disorders. The British Journal of Psychiatry 2005;186:190-6.

9. Jackson ER, Shanafelt TD, Hasan O, et al. Burnout and alcohol abuse/dependence among US medical students. Academic Medicine 2016;91:1251-6. 
10. Flagel SB, Waselus M, Clinton SM, et al. Antecedents and consequences of drug abuse in rats selectively bred for high and low response to novelty. Neuropharmacology 2014;76:425-36.

11. Finn PR, Mazas CA, Justus AN, Steinmetz J. Earlyonset alcoholism with conduct disorder: go/no go learning deficits, working memory capacity, and personality. Alcoholism: Clinical and Experimental Research 2002;26:186-206.

12. Brunes A, Augestad LB, Gudmundsdottir SL. Personality, physical activity, and symptoms of anxiety and depression: the HUNT study. Social psychiatry and psychiatric epidemiology 2013 May 1;48(5):745-56.

13. Rhodes RE, Smith NE. Personality correlates of physical activity: a review and meta-analysis. British journal of sports medicine 2006;40:958-65.

14. Yazici AB, Esen O, Yazici E, et al. The relationship between temperament and character traits and burnout among nurses. Journal of Psychology \& Psychotherapy 2014;4:1-5.

15. Stevens JP. Multiple regression. In Applied multivariate statistics for the social sciences 2012 (pp. 75-156). Routledge.

16. Soury A, Shabani Moghadam K, Soury R. The Effect of physical activity on quality of life in elder women in Kermanshah Province. Applied Research of Sport Management 2016;4: no.4, Spring. (Persian)

17. Dadfar M, Bahrami F, Dadfar F, Younesi S J. Reliability and Validity of the Temperament and Character Inventory. J rehab 2010;11(3):15-24. (Persian)

18. Naami AA. Relationship between quality of learning experiences and academic burnout in graduate students of Shahid Chamran University. Psychological Studies J 2009;5:117-34. (Persian)

19. Gerber M, Brand S, Elliot C, et al. Aerobic exercise training and burnout: a pilot study with male participants suffering from burnout. BMC Research Notes 2013;6:78.
20. Brand S, Gerber M, Beck J, Hatzinger M, et al. Exercising, sleep-EEG patterns, and psychological functioning are related among adolescents. The World Journal of Biological Psychiatry. 2010;11:129-40.

21. Shirom A, Melamed S, Toker S, et al. Burnout and health review: Current knowledge and future research directions. International review of industrial and organizational psychology 2005;20:269-308.

22 Parker G, Crawford J. Judged effectiveness of differing antidepressant strategies by those with clinical depression. Australian and New Zealand journal of psychiatry 2007;41:32-7.

23. Lindwall $M$, Ljung $T$, Hadžibajramović $E$, Jonsdottir IH. Self-reported physical activity and aerobic fitness are differently related to mental health. Mental Health and Physical Activity 2012;5:28-34.

24. Toker S, Biron M. Job burnout and depression: unraveling their temporal relationship and considering the role of physical activity. Journal of Applied Psychology 2012;97:699.

25. Jonsdottir IH, Rödjer L, Hadzibajramovic E, et al. A prospective study of leisure-time physical activity and mental health in Swedish health care workers and social insurance officers. Preventive medicine 2010;51:373-7.

26. Schaufeli W, Enzmann D. The burnout companion to study and practice: A critical analysis. CRC press; 1998 Nov 17.

27. Suls J, Bunde J. Anger, anxiety, and depression as risk factors for cardiovascular disease: the problems and implications of overlapping affective dispositions. Psychological bulletin 2005;131:260.

28. Beck AT, Steer RA, Carbin MG. Psychometric properties of the Beck Depression Inventory: Twenty-five years of evaluation. Clinical psychology review 1988;8:77-100.

Submission: Novamber, 1, 2019

Acceptance: December 12, 2019 